\title{
Learning HIP: Speaking the Language of Healthcare
}

\author{
Matthew Wilcox, MPH, Sarah E. Wiehe, MD, MPH, Brenda L. Hudson, MA, Fiona
} Schicho, Ivan D. Hicks, PhD, Andrew Green, MA, David M. Craig, PhD

\section{Background}

The Healthy Indiana Plan serves as an insurance program, expansion of Medicaid, and unique initiative of Indiana, serving citizens near the poverty line. Elements of the program like the distinction between HIP Plus and HIP Basic, as well as the Gateway to Work program and their effects on the community have yet to be fully understood in their impact on healthcare decision making, stimulating personal responsibility, and ER utilization rates. Churches and faithbased organizations have consistently provided model forms of health support supplementation for reaching community, especially as demonstrated in the work of First Baptist Church North Indianapolis and Shepherd Community Church of the Nazarene.

\section{Project Methods}

18 previously conducted and transcribed interviews with community leaders and community members were deductively analyzed with qualitative assessments, specifically descriptive content analysis and later framework analysis. Key themes and a framework were developed to understand and clarify responses and to produce direct recommendations.

\section{Results}

Participants in HIP Plus enjoy their insurance and experience minimal difficulty in receiving prescriptions and tests. However, remaining on HIP Plus is difficult for many participants, with the fallback of HIP Basic requiring copays that many are unable or unwilling to pay in light of greater financial priorities. Important factors arose, including: threshold knowledge to gain and maintain access, community necessitated assistance (advisory and financial), easy loss of HIP Plus status, gateway to work's incompatibility with seasonal/temporal work, and no central administrative hub to check HIP status. Successful participants are adamant about their insurance, using phone calls, office visits, or consistent communication with navigators to ensure HIP Plus status.

\section{Conclusion \& Future Directions}

This study, as well as Worlds Apart: Gaps in Life Expectancy in the Indianapolis Metro Area, have contributed to a continuing study on health inequity, community perspective, and organizational activities in Indianapolis communities. 